\section{RMD Open}

Rheumatic \&

Musculoskeletal Diseases

\title{
Is there a relationship between spondyloarthritis and periodontitis? A case-control study
}

\author{
Wilson Bautista-Molano, ${ }^{1,2,3}$ Desirée van der Heijde, ${ }^{1}$ \\ Robert Landewé, ${ }^{4,5}$ Gloria I Lafaurie, ${ }^{3}$ Juliette de Ávila, ${ }^{3}$ Rafael Valle-Oñate, ${ }^{2}$ \\ Consuelo Romero-Sanchez ${ }^{2,3}$
}

To cite: Bautista-Molano W, van der Heijde D, Landewé $\mathrm{R}$, et al. Is there a relationship between spondyloarthritis and periodontitis? A casecontrol study. RMD Open 2017;3:e000547. doi:10.1136/ rmdopen-2017-000547

- Prepublication history for this paper is available online. To view these files, please visit the journal online (http://dx.doi. org/10.1136/rmdopen-2017000547).

Received 30 July 2017

Revised 31 October 2017

Accepted 1 November 2017

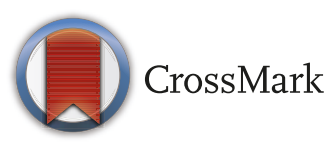

${ }^{1}$ Rheumatology Department, Leiden University Medical Center, Leiden, The Netherlands ${ }^{2}$ Rheumatology Department, School of Medicine, Universidad Militar Nueva Granada and Hospital Militar, Bogota, Colombia

${ }^{3}$ Unit of Oral Basic Investigation, School of Dentistry, Universidad El Bosque, Bogotá, Colombia ${ }^{4}$ Amsterdam Rheumatology \& Clinical Immunology Center, Amsterdam, The Netherlands ${ }^{5}$ Zuyderland Medical Center Heerlen, Heerlen, The Netherlands

\section{Correspondence to} Dr Wilson Bautista-Molano; wilson.bautista@gmail.com

\section{ABSTRACT}

Objective To compare the frequency and severity of periodontitis in patients with spondyloarthritis (SpA) with healthy control individuals, through the evaluation of clinical, serological and microbiological periodontal condition.

Methods Patients with a diagnosis of $\operatorname{SpA}(n=78)$ and biological disease-modifying antirheumatic drug (bDMARD) naive fulfilling the Assessment of SpondyloArthritis international Society (ASAS) classification criteria as well as 156 healthy controls matched for age/gender were included. Two trained and calibrated periodontologists performed the periodontal clinical assessment. The presence of periodontitis and its severity were determined according to the criteria established by the Centers for Disease Control and Prevention-American Academy of Periodontology. The clinical periodontal variables, IgG1/lgG2 antibodies against Porphyromonas gingivalis andperiodontopathic bacterial identification, were also established. Comparisons of periodontal characteristics between the patients with SpA and the control group were performed using univariable analyses. A logistic regression analyses was performed to calculate the $\mathrm{OR}(95 \% \mathrm{Cl})$ for diagnosis of periodontitis in patients with $\mathrm{SpA}$ and matched controls.

Results A diagnosis of periodontitis was established in $56 \%$ in patients with SpA versus $69 \%$ of healthy controls $(P \leq 0.01)$. Severe periodontitis was found in $3 \%$ versus $12 \%$ in SpA versus healthy controls, respectively $(P \leq 0.01)$. There was no significant increase of frequency of any periodontal variable, IgG1/lgG2 antibodies against $P$. gingivalis or the presence of periodontopathic bacteria between patients with $\mathrm{SpA}$ and control group. Periodontitis was not positively associated with a diagnosis of $\mathrm{SpA}$ (OR: $0.57,95 \% \mathrm{Cl} 0.32$ to $1.00, \mathrm{P}=0.05$ ) in the logistic regression analyses.

Conclusions We found a lower rather than a higher frequency and severity of periodontitis in patients with SpA in comparison with healthy control individuals. Our findings suggest that there is no positive association between $\mathrm{SpA}$ and periodontitis in Colombian patients.

\section{INTRODUCTION}

Spondyloarthritis (SpA) is a chronic rheumatic disease presenting with axial

\section{Key messages}

What is already known about this subject?

- Unlike spondyloarthritis $(\mathrm{SpA})$ in which it is still unclear whether patients with SpA have a higher frequency of periodontitis, rheumatoid arthritis (RA) has been associated with an increased prevalence of periodontitis and the risk of developing RA.

What does this study add?

- We have found a lower frequency and severity of periodontitis in patients with $\mathrm{SpA}$ in comparison with healthy control individuals, suggesting that there is no association between SpA and periodontitis.

How might this impact on clinical practice?

- There is no indication that evaluation of the periodontal condition is particularly necessary in patients with $\mathrm{SpA}$ as compared with other individuals.

spondyloarthritis (axSpA) and peripheral spondyloarthritis (pSpA) manifestations. ${ }^{1}$ This condition that is characterised by inflammation of the spine and peripheral joints has been associated with other inflammatory diseases such as uveitis, psoriasis and inflammatory bowel disease.$^{23}$ Chronic periodontitis is a common worldwide and chronic inflammatory condition characterised by progressive destruction of periodontal ligament and alveolar bone. ${ }^{4}$

Results from studies point towards a potential relationship between periodontitis and systemic rheumatic diseases, in particular rheumatoid arthritis (RA). ${ }^{5}$ Studies have found that the presence of RA has been associated with an increased prevalence of periodontitis and also with a significant inflammatory periodontal involvement in early disease. ${ }^{6} 7$ Periodontitis has been considered as a condition that influences 
the risk of developing RA in first-degree relatives. ${ }^{8}$ Moreover, important mechanisms that characterise the pathogenesis of RA are also involved in the pathogenesis of periodontitis. ${ }^{9}$ Many studies have suggested that extra-articular citrullination is an immunological event that may occur in periodontal tissue under inflammatory conditions. ${ }^{10}$ Following this reasoning, the citrullination and the induction of anticitrullinated peptide antibodies (ACPAs) has emerged as a biochemical process that may initiate the cascade of events leading to inflammation in RA. ${ }^{11}$

Knowledge of the existence of an epidemiological association between SpA and periodontitis may fuel pathophysiological thinking about SpA and, if established, have clinical implications. Currently, it is unclear whether patients with SpA have a higher frequency of periodontitis, and data in the literature reporting a possible association are limited. Therefore, the aim of the present study was to compare the frequency and severity of periodontitis in patients with SpA with age/ gender-matched healthy individuals through the evaluation of the clinical, serological and microbiological periodontal condition.

\section{METHODS}

\section{Study subjects}

Consecutive adult patients with a diagnosis of SpA $(n=78)$ and fulfilling Assessment of SpondyloArthritis international Society (ASAS) classification criteria ${ }^{1213}$ attending a rheumatology outpatient clinic in an academic centre for routine care in Colombia were selected. A control group of 156 individuals from the general population (between 18 and 65 years) matched for gender and age (maximum difference of 1 year) were enrolled. Healthy individual volunteers were recruited among persons accompanying the patients to medical appointments in several departments of the hospital. Additionally, people working and living near the hospital were invited to participate. All controls were specifically questioned and were excluded from this study if they reported a history of rheumatological diseases. Exclusion criteria for cases and controls were use of antibiotics during the last 3 months and a history of periodontal or orthodontic therapy. All individuals completed a specific questionnaire addressing medical history, demographics, body mass index and smoking. Information related to current and previous treatment was collected. Disease activity in patients with SpA was assessed using the Ankylosing Spondylitis Disease Activity Score (ASDAS) for C reactive protein (CRP). ${ }^{14}$ As tumour necrosis factor (TNF)-alpha has an important role in the pathogenesis of periodontitis and TNF-alpha blockers have been considered as a factor that may influence the periodontal condition, all patients with SpA included in this study were biological disease-modifying antirheumatic drugs (bDMARD) naive. Study subjects provided written informed consent.

\section{Periodontal assessment}

Two trained and calibrated periodontologists with intrareader and inter-reader agreement $\geq 0.9$ with the standard performed the periodontal clinical assessment. ${ }^{15}$ Periodontologists were blinded to the group category of the individuals (patients or controls) at the time of evaluation. Each patient and/or control was examined by one of both periodontologists, and each periodontologist assessed $50 \%$ of all patients and controls. Using a North Carolina probe (Hu-Friedy PCPUNC-15), a full-mouth examination at six sites on each permanent tooth was performed. The periodontal variables assessed were as follows: clinical attachment loss (CAL), pocket probing depth (PD), insertion level total mouth, plaque index and gingival index.

The presence of periodontitis and its severity were defined according to the criteria established by the Centers for Disease Control and Prevention-American Academy of Periodontology (CDC-AAP) ${ }^{16}$ According to these criteria, the definitions were based on measures of CAL and PD at the four interproximal sites per tooth. Periodontitis was defined as $\geq 2$ interproximal sites with CAL $\geq 4 \mathrm{~mm}$ or $\geq 2$ interproximal sites with $\mathrm{PD} \geq 5 \mathrm{~mm}$ (not on same tooth). Severe periodontitis was defined as $\geq 2$ interproximal sites with CAL $\geq 6 \mathrm{~mm}$ (not on same tooth) or $\geq 1$ interproximal sites with probing depth $\geq 5 \mathrm{~mm}$.

\section{Laboratory testing}

The protocol employed for the detection of IgG1/IgG2 antibodies against Porphyromonas gingivalis has been previously standardised. ${ }^{7}$ To detect these antibodies, an indirect ELISA was performed in-house in 96-well plates. Each well was coated with $5 \mathrm{mg}$ of a sonicated preparation of whole $P$. gingivalis ATCC33277 and W83 strains. For bacterial identification, the following procedure was performed: after removing supragingival plaque with curettes and previous relative isolation with cotton rolls, a tip of sterile paper (calibre 40-NewStetic) was placed in the gingival sulcus for $20 \mathrm{~s}$ in six of the deepest sites of each patient. The paper tips of each site were placed in a sterile tube and processed for bacterial by quantitative PCR. ${ }^{17}$ The results for plaque samples were projected on the standard curve generated with $P$. gingivalis (ATCC 33277), Treponema denticola (ATCC 35405) and Tannerella forsythia (ATCC 43037) and transformed to $\log 10$.

\section{Statistical analysis}

Descriptive analyses were used to calculate means (SD) for continuous data and percentages for categorical data. The frequencies of periodontitis, severity, periodontal variables, IgG1/IgG2 antibodies against $P$. gingivalis and bacterial identification were established. Comparisons of periodontal characteristics between patients with SpA and control individuals were performed using univariable analyses. For variables with a normal distribution, parametric t tests were used. For variables with a non-normal distribution, differences between cases and controls were 
compared by McNemar test for categorical variables or Wilcoxon signed test for continuous variables. A logistic regression analysis was performed with the diagnosis of periodontitis as a dependent variable. ORs with $95 \%$ CI were calculated. All analyses were performed at a significance level of 5\%. The statistical package STATA V.12 was used.

\section{RESULTS}

\section{Demographics and clinical characteristics}

In total 78 patients in the SpA group and 156 individuals in the healthy control group were matched by age and gender. In the SpA group, the mean age was 39.6 (11), $60 \%$ were men and the distribution by subtypes was as follows: ankylosing spondylitis (AS) $(n=25)$, non-radiographic axSpA $(n=41)$ and $\mathrm{pSpA}(\mathrm{n}=12)$. Patients with SpA had a mean disease duration of 5.0 (7.1) years and ASDAS of $2.7(0.8)$. Of the SpA patients $45 \%$ was HLAB27 positive. In total, $82 \%$ of patients with SpA were receiving non-steroidal anti-inflammatory drugs (NSAIDS) and 49\% were receiving sulphasalazine.

\section{Periodontal clinical assessment}

In the group of SpA, $56 \%$ had a diagnosis of periodontitis, compared with $69 \%$ in the control group $(\mathrm{P}=0.01)$, according to the parameters of the CDC-AAP. In total, $2.6 \%$ had severe periodontitis in contrast to $12.2 \%$ in the control group ( $\mathrm{P}=0.01)$. CAL was less severe in SpA (1.9 $(0.6) \mathrm{mm})$ as compared with controls $(2.4(0.8) \mathrm{mm})$ $(\mathrm{P} \leq 0.001)$. Additionally, the total in-mouth insertion level was found to be lower in patients with SpA (2.4 (0.5) $\mathrm{mm})$ in comparison with their matched controls (2.9 $(0.8) \mathrm{mm})(\mathrm{P} \leq 0.001)$. Results are presented in table 1. In the logistic regression analyses, periodontitis was not positively but negatively associated with $\mathrm{SpA}(\mathrm{OR}=0.57$, $95 \%$ CI 0.32 to $1.00, \mathrm{P}=0.05$ ).

\section{Antibodies and bacterial identification}

There was no significant increase of frequency with regard to IgG1/IgG2 antibodies against $P$. gingivalis and the presence of periodontopathic bacteria between SpA patients and healthy controls (table 1 ).

\section{DISCUSSION}

The results of this case-control study suggest that-unlike the situation in RA-there is not a positive association between SpA and periodontitis in Colombian patients. We even found a lower prevalence of periodontitis and less severe periodontitis in comparison with healthy controls. Moreover, all periodontal characteristics evaluated including clinical parameters, antibodies anti $P$. gingivalis and bacterial identification were not increased in patients with SpA as compared with controls.

Several studies on the association between periodontitis and RA have been published. ${ }^{18}$ Periodontitis has been considered a condition with an increased prevalence in individuals with RA and also has been related
Table 1 Characteristics and periodontal variables in patients with spondyloarthritis (SpA) and healthy controls

\begin{tabular}{lccl}
\hline Characteristics & $\begin{array}{l}\text { SpA } \\
(\mathbf{n = 7 8 )}\end{array}$ & $\begin{array}{l}\text { Controls } \\
(\mathbf{n = 1 5 6 )}\end{array}$ & $\begin{array}{l}\text { P } \\
\text { value }\end{array}$ \\
\hline Age (years) & $39.6(11.0)$ & $39.5(11.1)$ & $*$ \\
\hline Male gender (n (\%)) & $47(60.3)$ & $94(60.3)$ & $*$ \\
$\begin{array}{l}\text { Smoking (currently) } \\
\text { (n (\%)) }\end{array}$ & $11(14.1)$ & $14(9.0)$ & 0.14 \\
$\begin{array}{l}\text { Obesity (BMI } \geq 30) \\
\text { (n (\%)) }\end{array}$ & $6(7.6)$ & $16(10.2)$ & 0.43 \\
$\begin{array}{l}\text { Periodontitis } \\
\text { (positive)† (n (\%)) }\end{array}$ & $44(56.4)$ & $108(69.2)$ & 0.01 \\
\hline
\end{tabular}

Severity of

periodontitis $†$

(n (\%))

\begin{tabular}{|c|c|c|c|}
\hline None & $34(43.6)$ & $48(30.8)$ & 0.01 \\
\hline Mild & $11(14.1)$ & 20 (12.8) & \\
\hline Moderate & 31 (39.7) & 69 (44.2) & \\
\hline Severe & $2(2.6)$ & 19 (12.2) & \\
\hline $\begin{array}{l}\text { Insertion level total } \\
\text { mouth }(\mathrm{mm})\end{array}$ & $2.4(0.5)$ & $2.9(0.8)$ & $<0.001$ \\
\hline $\begin{array}{l}\text { CAL average } \\
\text { interproximal }(\mathrm{mm})\end{array}$ & $1.9(0.6)$ & $2.3(0.8)$ & $<0.001$ \\
\hline $\begin{array}{l}\text { Total pocket depth } \\
\text { mouth }(\mathrm{mm})\end{array}$ & $3.3(1.7)$ & $3.2(1.9)$ & 0.29 \\
\hline Plaque index (\%) & $0.4(0.2)$ & $0.5(0.2)$ & 0.12 \\
\hline Gingival index (\%) & $0.3(0.2)$ & $0.4(0.5)$ & 0.33 \\
\hline $\begin{array}{l}\text { Number of teeth } \\
\text { present }\end{array}$ & $26.1(4.1)$ & $25.5(5.4)$ & 0.79 \\
\hline $\begin{array}{l}\text { Porphyromonas } \\
\text { gingivalis (presence) } \\
\mathrm{n}(\%)\end{array}$ & $23(29.4)$ & $71(45.5)$ & $<0.01$ \\
\hline $\begin{array}{l}\text { Treponema } \\
\text { denticola (presence) } \\
\mathrm{n}(\%)\end{array}$ & 13 (16.6) & $84(53.8)$ & $<0.001$ \\
\hline $\begin{array}{l}\text { Tannerella forsythia } \\
\text { (presence) n (\%) }\end{array}$ & $6(7.6)$ & 75 (48.1) & $<0.001$ \\
\hline $\begin{array}{l}\text { IgG1 anti } P \text {. } \\
\text { gingivalis (positive) } \\
\mathrm{n}(\%)\end{array}$ & $40(51.2)$ & $80(51.2)$ & 1 \\
\hline $\begin{array}{l}\text { IgG2 anti } P \text {. } \\
\text { gingivalis (positive) } \\
\mathrm{n}(\%)\end{array}$ & $41(52.5)$ & $74(47.4)$ & 0.32 \\
\hline
\end{tabular}

All values given as mean (SD) unless specified.

${ }^{*}$ Age and gender were matching criteria.

†Criteria and severity definition according to the Centers for Disease Control and Prevention-American Academy of Periodontology (CDC-AAP).

BMI, body mass index; CAL, clinical attachment loss.

to the progression of inflammatory involvement in these patients. ${ }^{19}$ In contrast, in the current study, we did not find a relationship between SpA and periodontitis. Patients with SpA do not share the same genetic risk factors, female predominance and disease-specific 
autoantibodies such as ACPAs with RA. The citrullination of proteins, which has been suggested the 'link' behind the association between RA and periodontitis, is a biochemical process that has not been found relevant in the pathogenesis of SpA. ${ }^{20}$ Moreover, the prominent role of HLA-B27 in SpA has not been involved in the pathophysiology of periodontitis. To our knowledge, there is no data evaluating the potential contribution of the allele HLA-B27 in the pathogenesis of periodontitis.

A potential association between SpA and periodontitis has been investigated in previous studies. In a study including 51 patients with psoriatic arthritis, the frequency of periodontitis was similar and statistically not different compared with control subjects $(41 \%$ vs $38 \%$, respectively) $(\mathrm{P}=0.90) .{ }^{21}$ In contrast, a case-control study in Germany including 48 patients with AS reported a significantly higher risk of periodontal disease compared with controls (OR=5.4, 95\% CI 1.4 to 22.0$).{ }^{22}$ However, the case definition of periodontal disease in this study was based on a clinical measure (CAL $\geq 3 \mathrm{~mm}$ ) instead of a clinical diagnosis or established criteria. Moreover, a study using administrative claims data sourced from the National Health Insurance programme in Taiwan reported that patients with AS were 1.8 times more likely to have a previous diagnosis of chronic periodontitis than controls (OR=1.8, 95\% CI 1.7 to 1.9$)$. However, all the cases of periodontitis analysed in this study were sourced from an administrative database, which may be less accurate than a clinical diagnosis made by periodontologists. Recently, a systematic review and meta-analysis including six case-control studies reported a prevalence rate of periodontitis that ranged from $38 \%$ to $88 \%$ in patients with AS versus a range from $26 \%$ to $71 \%$ in controls. ${ }^{23}$ Although the authors report an increasing risk of AS associated with periodontitis ( $\mathrm{OR}=1.85,95 \%$ CI 1.7 to 1.9$)$, the potential confounding factors, high level of heterogeneity and methodological weaknesses among the few eligible studies may limit the interpretation of the results. Moreover, the different case definitions of periodontitis used in these studies may have influenced the prevalence of periodontitis and hamper to establish clear associations and comparisons between studies.

Our study has strengths and weaknesses. The main limitations are the cross-sectional design, which complicates the generation of causal inferences.

In addition, while controls without periodontological complaints were specifically looked for, it cannot be excluded that we have selected some controls that actually did have complaints and were particularly interested in taking part. This would explain why periodontitis was found more frequently in controls than in patients with SpA (recruitment bias). Moreover, there is a limited sample size. However, without a signal at all in any of the periodontitis parameters, it is unlikely that a larger sample size would yield fundamentally different results. Among the strengths of this study are the comprehensive periodontal assessment that had been performed, in addition to the serological and microbiological investigations for the comparison of cases and controls. To our knowledge, this is one of the first studies assessing the periodontal condition in the full spectrum of SpA including patients with axSpA and pSpA. Moreover, all patients with SpA included were not previously or currently exposed to TNF blockers. TNF-alpha has an important role in the pathogenesis of periodontitis. Medications such as TNF blockers have been considered as a factor that may influence the risk of periodontitis and even improve the periodontal condition. ${ }^{24}$ In this study, we have avoided such potential confounding.

A higher percentage of patients were taking NSAIDs and sulphasalazine, and the effect of these medications with regard to the modulation of periodontal condition has not been clearly established. In theory, NSAID usage and sulphasalazine may have jeopardised the detection of periodontitis in the SpA group. While multiple studies have investigated the effect of NSAIDs on the periodontal condition in terms of reducing gingival inflammation and influencing alveolar bone loss, ${ }^{25}{ }^{26}$ more information is needed investigating the role of NSAIDs and disease-modifying antirheumatic drugs (DMARDs) as modulatory agents of periodontal disease progression in patients with $\mathrm{SpA} .{ }^{27} 28 \mathrm{~A}$ recent study, for instance, has suggested that conventional DMARDs may have a modifying effect on the periodontal condition in patients with RA: patients receiving the combination of methotrexate plus leflunomide had worse CAL. ${ }^{29}$

A point of concern may be the high prevalence of periodontitis in the Colombian general population. Such a high prevalence in the control population-if spuriously high-may in theory jeopardise the detection of a contrast between patients with SpA and controls. A nationwide population study led by the Colombian Ministry of Health reporting on the oral health status in adults $\geq 18$ years old Estudio Nacional de Salud Bucal (ENSAB IV) found a prevalence of periodontitis of $62 \% .^{30}$ Moreover, a higher percentage of men had periodontitis in comparison with women $(67 \%$ vs $58 \%)$. This national data are in concordance with the prevalence found in the control group in the current study, taking into account that SpA has a male predominance and the sample had been matched by gender. This finding implies that Colombia may have a higher prevalence of periodontal disease than other countries such as the USA $(47 \%)^{31}$ or Germany $(51 \%){ }^{32}$ In this context, country-specific differences with regard to the prevalence of periodontitis in the general population should be considered in the interpretation and the external validity of our findings.

In conclusion we have found a lower rather than a higher frequency and severity of periodontitis in patients with SpA in comparison with healthy control individuals in a sample of Colombian patients.

Acknowledgements The authors would like to thank to Diana M Castillo $P$ and Lorena Chila-Moreno for the assistance and her work performing the bacteria identification analyses and the detection of the autoantibodies. Additionally special thanks to Maria Fernanda Torres and Luz Amparo Rodriguez for their work in the periodontal clinical assessment and to Juan Manuel Bello for the selection of 
patients. This study was supported by the Universidad El Bosque (PCI 2013-469), the Hospital Militar Central (2013-048), and the Government Institute of Science, Technology, and Innovation, Francisco Jose de Caldas-COLCIENCIAS (Grant No. 130854531734-2011 and 130865740792). We also would like to acknowledge the presentation of the article at ACR (cite of the published abstract): BautistaMolano W, van der Heijde D, Landewé RBM, et al. Is there a relationship between spondyloarthritis and periodontitis? A case-control study [abstract]. Arthritis Rheumatol 2017;69(Suppl 10). http://acrabstracts.org/abstract/is-there-a-relat ionship-betweenspondyloarthritis-and-periodontitis-a-case-control-study/.

Contributors WB-M, DvdH, RL and CR-S designed the study. WB-M, GIL and CR-S acquired the data. WB-M and GIL analysed the data. WB-M, DvdH, RL and CR-S oversaw the analysis. WB-M prepared the first version of the manuscript. All authors critically revised the manuscript for important intellectual content. All authors gave their approval of the final version of the manuscript.

Competing interests None declared.

Patient consent Obtained.

Ethics approval The institutional ethics committees of Universidad El Bosque and Hospital Militar approved the study.

Provenance and peer review Not commissioned; externally peer reviewed.

Data sharing statement № additional data are available.

Open Access This is an Open Access article distributed in accordance with the Creative Commons Attribution Non Commercial (CC BY-NC 4.0) license, which permits others to distribute, remix, adapt, build upon this work non-commercially, and license their derivative works on different terms, provided the original work is properly cited and the use is non-commercial. See: http://creativecommons.org/ licenses/by-nc/4.0/

(C) Article author(s) (or their employer(s) unless otherwise stated in the text of the article) 2017. All rights reserved. No commercial use is permitted unless otherwise expressly granted.

\section{REFERENCES}

1. Dougados M, Baeten D. Spondyloarthritis. Lancet 2011;377:2127-37.

2. Stolwijk C, van Tubergen A, Castillo-Ortiz JD, et al. Prevalence of extra-articular manifestations in patients with ankylosing spondylitis: a systematic review and meta-analysis. Ann Rheum Dis 2015;74:65-73.

3. Sengupta R, Stone MA. The assessment of ankylosing spondylitis in clinical practice. Nat Clin Pract Rheumatol 2007;3:496-503.

4. Page RC, Kornman KS. The pathogenesis of human periodontitis: an introduction. Periodontol 2000 1997;14:9-11.

5. de Pablo P, Chapple IL, Buckley CD, et al. Periodontitis in systemic rheumatic diseases. Nat Rev Rheumatol 2009;5:218-24.

6. de Pablo P, Dietrich T, McAlindon TE. Association of periodontal disease and tooth loss with rheumatoid arthritis in the US population. J Rheumatol 2008;35:70-6.

7. Bello-Gualtero JM, Lafaurie GI, Hoyos LX, et al. Periodontal disease in individuals with a genetic risk of developing arthritis and early rheumatoid arthritis: a cross-sectional Study. J Periodontol 2016;87:346-56.

8. Unriza-Puin S, Bautista-Molano W, Lafaurie GI, et al. Are obesity, ACPAs and periodontitis conditions that influence the risk of developing rheumatoid arthritis in first-degree relatives? Clin Rheumatol 2017;36:799-806.

9. van der Helm-van Mil AH, Huizinga TW. Advances in the genetics of rheumatoid arthritis point to subclassification into distinct disease subsets. Arthritis Res Ther 2008;10:205.

10. Bright R, Proudman SM, Rosenstein ED, et al. Is there a link between carbamylation and citrullination in periodontal disease and rheumatoid arthritis? Med Hypotheses 2015;84:570-6.
11. van Gaalen F, loan-Facsinay A, Huizinga TW, et al. The devil in the details: the emerging role of anticitrulline autoimmunity in rheumatoid arthritis. J Immunol 2005;175:5575-80.

12. Rudwaleit $M$, van der Heijde $D$, Landewé $R$, et al. The development of Assessment of spondyloArthritis international society classification criteria for axial spondyloarthritis (part II): validation and final selection. Ann Rheum Dis 2009;68:777-83.

13. Rudwaleit M, van der Heijde D, Landewé R, et al. The assessment of spondyloarthritis international society classification criteria for peripheral spondyloarthritis and for spondyloarthritis in general. Ann Rheum Dis 2011;70:25-31.

14. Machado PM, Landewé RB, van der Heijde DM. Endorsement of definitions of disease activity states and improvement scores for the ankylosing spondylitis disease activity score: results from OMERACT 10. J Rheumatol 2011;38:1502-6.

15. Lafaurie Gl, Contreras A, Barón A, et al. Demographic, clinical, and microbial aspects of chronic and aggressive periodontitis in Colombia: a multicenter study. J Periodontol 2007;78:629-39.

16. Page RC, Eke PI. Case definitions for use in population-based surveillance of periodontitis. J Periodontol 2007;78:1387-99.

17. Boutaga K, van Winkelhoff AJ, Vandenbroucke-Grauls CM, et al. Comparison of real-time PCR and culture for detection of Porphyromonas gingivalis in subgingival plaque samples. J Clin Microbiol 2003;41:4950-4.

18. Rutger Persson G. Rheumatoid arthritis and periodontitis inflammatory and infectious connections. Review of the literature. J Oral Microbiol 2012;4

19. Lundberg K, Wegner N, Yucel-Lindberg T, et al. Periodontitis in RA-the citrullinated enolase connection. Nat Rev Rheumatol 2010;6:727-30.

20. Lappin DF, Apatzidou D, Quirke AM, et al. Influence of periodontal disease, Porphyromonas gingivalis and cigarette smoking on systemic anti-citrullinated peptide antibody titres. J Clin Periodontol 2013;40:907-15

21. Üstün K, Sezer U, Kısacık B, et al. Periodontal disease in patients with psoriatic arthritis. Inflammation 2013;36:665-9.

22. Pischon N, Pischon T, Gülmez E, et al. Periodontal disease in patients with ankylosing spondylitis. Ann Rheum Dis 2010;69:34-8.

23. Ratz T, Dean LE, Atzeni F, et al. A possible link between ankylosing spondylitis and periodontitis: a systematic review and meta-analysis. Rheumatology 2015;54:500-10.

24. Soory M. Periodontal diseases and rheumatoid arthritis: a coincident model for therapeutic intervention? Curr Drug Metab 2007;8:750-7.

25. Vogel RI, Copper SA, Schneider LG, et al. The effects of topical steroidal and systemic nonsteroidal anti-inflammatory drugs on experimental gingivitis in man. J Periodontol 1984;55:247-51.

26. Johnson $\mathrm{RH}$, Armitage GC, Francisco C, et al. Assessment of the efficacy of a nonsteroidal anti-inflammatory drug, naprosyn, in the treatment of gingivitis. J Periodontal Res 1990;25:230-5.

27. Salvi GE, Lang NP. The effects of non-steroidal anti-inflammatory drugs (selective and non-selective) on the treatment of periodontal diseases. Curr Pharm Des 2005;11:1757-69.

28. Howell TH, Williams RC. Nonsteroidal antiinflammatory drugs as inhibitors of periodontal disease progression. Crit Rev Oral Biol Med 1993:4:177-96.

29. Romero-Sanchez C, Rodríguez C, Santos-Moreno P, et al. Is the treatment with biological or non-biological DMARDS a modifier of periodontal condition in patients with rheumatoid arthritis? Curr Rheumatol Rev 2017;13:139-51.

30. Ministerio de SaludEstudio nacional de salud bucal ENSAB IV. Situación de salud bucal. sistema internacional de clasificación de la enfermedad periodontal y condiciones asociadas. Bogotá (DC): Ministerio de Salud, 2014

31. Eke PI, Dye BA, Wei L, et al. Prevalence of periodontitis in adults in the United States: 2009 and 2010. J Dent Res 2012;91:914-20.

32. Holtfreter B, Schwahn C, Biffar R, et al. Epidemiology of periodontal diseases in the study of health in pomerania. J Clin Periodontol 2009;36:114-23. 